\title{
Article \\ Novel Hydroxyapatite Beads for the Adsorption of Radionuclides from Decommissioned Nuclear Power Plant Sites
}

\author{
Thi Nhung Tran ${ }^{1} \mathbb{D}$, Junho Kim ${ }^{1} \mathbb{D}$, Joo-Sung Park ${ }^{1}$, Youngkun Chung ${ }^{1}$, Jaemun Han ${ }^{2}$, Seungjun Oh ${ }^{2}$ \\ and Seoktae Kang $1, *$ (D)
}

1 Department of Civil and Environmental Engineering, Korea Advanced Institute of Science and Technology (KAIST), 291 Daehak-ro, Yuseong-gu, Daejeon 34141, Korea; trannhung@kaist.ac.kr (T.N.T.); kjh2020@kaist.ac.kr (J.K.); jspark235@kaist.ac.kr (J.-S.P.); jyk0524@kaist.ac.kr (Y.C.)

2 Hyundai Engineering \& Construction, Hyundai Bldg. 75, Yulgok-ro, Jongno-gu, Seoul 03058, Korea; jmhan@hdec.co.kr (J.H.); ohseungjun@hdec.co.kr (S.O.)

* Correspondence: stkang@kaist.ac.kr; Tel.: +82-42-350-3635

Citation: Tran, T.N.; Kim, J.; Park, J.-S.; Chung, Y.; Han, J.; Oh, S.; Kang, S. Novel Hydroxyapatite Beads for the Adsorption of Radionuclides from Decommissioned Nuclear Power Plant Sites. Appl. Sci. 2021, 11, 1746. https://doi.org/10.3390/app11041746

Academic Editor: Ki-Hyun Kim Received: 18 January 2021

Accepted: 9 February 2021

Published: 16 February 2021

Publisher's Note: MDPI stays neutral with regard to jurisdictional claims in published maps and institutional affiliations.

Copyright: (c) 2021 by the authors. Licensee MDPI, Basel, Switzerland. This article is an open access article distributed under the terms and conditions of the Creative Commons Attribution (CC BY) license (https:// creativecommons.org/licenses/by/ $4.0 /)$.

\begin{abstract}
Although a powdered form of hydroxyapatite ( $\mathrm{p}-\mathrm{HdA}$ ) has been studied for the adsorption of heavy metals that contaminate the restoration sites of decommissioned nuclear power plants, most of the studies are limited in the laboratory due to the head loss and post-separation in practical applications. Herein, we fabricated a porous bead form of $\mathrm{HdA}(\mathrm{b}-\mathrm{HdA})$ as a novel adsorbent for removing radionuclides from aqueous environments via a facile synthesis by mixing the $\mathrm{p}-\mathrm{HdA}$ precursor and polyvinyl butyral (PVB) as a binder and added a sintering process for the final production of a porous structure. The spherical b-HdA with an approximate diameter of $2.0 \mathrm{~mm}$ was successfully fabricated. The effectiveness of the b-HdA at removing $\mathrm{Co}$ (II) was investigated via the adsorption equilibrium at various experimental temperatures. The b-HdA exhibited the adsorption capacity for Co(II) ions with a maximum of 7.73 and $11.35 \mathrm{mg} / \mathrm{g}$ at $293 \mathrm{~K}$ and $313 \mathrm{~K}$, respectively. The experimental kinetic data were well described using a pseudo-second-order kinetic model, and the adsorption mechanisms of $\mathrm{Co}$ (II) onto the b-HdA were revealed to be a chemisorption process with intraparticle diffusion being the rate-limiting step. In addition, the competitive adsorption onto the b-HdA with the order of $\mathrm{U}(\mathrm{VI})>\mathrm{Co}(\mathrm{II})>\mathrm{Ni}(\mathrm{II})>\mathrm{Sr}(\mathrm{II})>\mathrm{Cs}(\mathrm{I})$ was also observed in the multiradionuclides system. Considering the advantages of the size, applicability to the continuous-flow column, and the easy separation from treated water, the b-HdA can be an excellent absorbent with high potential for practical applications for removing radionuclides.
\end{abstract}

Keywords: adsorption; cobalt; hydroxyapatite; isotherms; kinetics; thermodynamics; radionuclides

\section{Introduction}

In recent years, increasing attention has been paid to the removal of radioactive pollutants from aquatic ecosystems due to their frequent and widespread detection [1,2]. In addition to natural radionuclides, the occurrence of radioactive pollutants has become widely recognized due to their introduction through anthropogenic sources, such as nuclear power plants, weapons, medicine, industrial radiography, studies, accidental releases, and inadequate practices of radioactive waste disposal [3-5]. Among the various noxious radionuclides, ${ }^{137} \mathrm{Cs},{ }^{60} \mathrm{Co},{ }^{63} \mathrm{Ni},{ }^{55} \mathrm{Fe},{ }^{90} \mathrm{Sr},{ }^{226} \mathrm{Ra},{ }^{232} \mathrm{Th}$, and ${ }^{238} \mathrm{U}$ were reported as the key artificial radioactive contaminants [1-3]. Remarkably, ${ }^{60} \mathrm{Co}$ has been identified as a significant environmental issue because it generally prevailed in aqueous wastes that are discharged from nuclear facilities [3,6]. Ionizing radiation exposure has emerged as a serious public health issue due to its biologically dynamic toxicity via generating free radicals, which can damage, mutate, or even kill cells [7,8]. Although cobalt is a micronutrient, excessive cobalt exposure results in various health hazards, such as neurological and cardiovascular issues, endocrine deficits, bone defects, and cancers [4]. Given the harmful nature 
of such radionuclides, various methods have been proposed and developed to effectively control radionuclide ions in contaminated water, including reverse osmosis, membrane separation, adsorption, biological treatment, and electrodialysis $[3,5,7,8]$. Among them, adsorption has been widely investigated as the most cost-effective, environmentally friendly method and the easiest technique for industrial application $[9,10]$. In this regard, various types of adsorbents, including biomass, clays, activated carbon, hydroxyapatite, metal particulates, and metal oxides functionalized with bio-based substances have been used to separate contaminants during water treatment $[1,5,11]$.

Of them, hydroxyapatite $\left(\mathrm{Ca}_{10}\left(\mathrm{PO}_{4}\right)_{6}(\mathrm{OH})_{2}\right)$, a calcium phosphate, has emerged as one of the promising environmental remediation materials with low cost, nontoxicity, biocompatibility, and biodegradability properties [12]. The popularity lies in its particular structure and unique properties, such as its ion exchange capability, adsorptive ability, acidbase adjustability, and thermal stability [12-16]. The feasibility of hydroxyapatite (HdA) nanoparticles as effective adsorbents is well documented for the adsorption of various multi-valent metal ions, such as lead, cobalt, nickel, copper, zinc, cadmium, strontium, and uranium [1,17-19]. Indeed, the HdA has a versatile structure, which allows foreign ions to substitute Ca-ions on the framework without any distortion [20]. Nevertheless, the use of HdA nanoparticles in the industrial field is limited due to their difficulties in separating them from effluent and the possibility of causing secondary pollution [12]. The auxiliary separation steps, such as ultrafiltration or the sedimentation process, requires a significant amount of time, additional investment, and operation costs [21]. In addition, the application of powdered hydroxyapatite (p-HdA) for the continuous-flow column is impossible due to the significant head loss that is induced by the small size of HdA powders. Taking into account these issues, the fabrication of macro-sized HdA granules will enable easier separation in suspended applications, as well as lower head-loss during continuous-flow column applications.

For biomedical applications, several methods have been employed to fabricate a macro-structured $\mathrm{HdA}$, such as granulating via centrifugation and vibration, sintering, casting in plaster molds, and spraying [22-24]. Regarding environmental applications, only a few studies have been developed for water treatment so far. Nijhawan et al. [25,26] fabricated porous HdA ceramic beads $(4.0-5.0 \mathrm{~mm}$ ) by mixing the p-HdA and solute starch and sintering at $1200{ }^{\circ} \mathrm{C}$ for $2 \mathrm{~h}$ to adsorb the fluoride. Le et al. [27] mixed the p-HdA and polyvinyl alcohol (PVA) and calcinated at $600{ }^{\circ} \mathrm{C}$ for $4 \mathrm{~h}$ to obtain HdA pellets $(2.0 \times 10.0 \mathrm{~mm})$ with a maximum lead adsorption capacity of $7.99 \mathrm{mg} / \mathrm{g}$.

In this work, a facile and rapid preparation method for fabricating macro-sized HdA beads was developed from a mixture of polyvinyl butyral (PVB) and HdA for the application of continuous flow columns, and the adsorption of radionuclides, such as Co(II), ions in a single and multi-ionic system to simulate the treatability of radionuclides that originate from the decommissioning sites of nuclear power plants was verified. The equilibrium, kinetic, and thermodynamic adsorption experiments of b-HdA were conducted for $\mathrm{Co}$ (II) ions, and the experimental data were fitted with various equilibrium isotherms and kinetic models to obtain a deeper understanding of the adsorption behaviors and mechanisms.

\section{Materials and Methods}

\subsection{Material Preparation}

\subsubsection{Chemicals and Materials}

Powdered hydroxyapatite was purchased from OCI Company Ltd. (Seoul, Korea). Polyvinyl butyral $\left(\left(\mathrm{C}_{8} \mathrm{H}_{14} \mathrm{O}_{2}\right)_{n}\right)$ was obtained from Sinopharm Ltd. (Beijing, China). The other chemicals, such as cobalt chloride hexahydrate $\left(\mathrm{CoCl}_{2} \cdot 6 \mathrm{H}_{2} \mathrm{O}, 97.0 \%\right)$, nickel chloride hexahydrate $\left(\mathrm{NiCl}_{2} \cdot 6 \mathrm{H}_{2} \mathrm{O}, 97.0 \%\right)$, strontium chloride hexahydrate $\left(\mathrm{SrCl}_{2} \cdot 6 \mathrm{H}_{2} \mathrm{O},>99.0 \%\right)$, cesium chloride ( $\mathrm{CsCl}, 99.0 \%)$, nitric acid $\left(\mathrm{HNO}_{3}, 70 \%\right)$, and N-methyl-2-pyrrolidone (NMP) $\left(\mathrm{C}_{5} \mathrm{H}_{9} \mathrm{NO}, 99 \%\right)$ were supplied by Samchun Pure Chemical Co. (Seoul, Korea). Uranyl acetate $\left(\mathrm{UO}_{2}\left(\mathrm{CH}_{3} \mathrm{COO}\right)_{2} \cdot 2 \mathrm{H}_{2} \mathrm{O}, 99.8 \%\right)$ was supplied by Electron Microscopy Sciences Co. (Hatfield, PA, USA). 


\subsubsection{Preparation of Porous HdA Beads}

The porous bead form of $\mathrm{HdA}(\mathrm{b}-\mathrm{HdA})$ was fabricated by using the sintering method with p-HdA as a precursor and PVB as a binder and pore-forming agent. A mixture containing $2.0 \mathrm{~g}$ of PVB and $18.0 \mathrm{~g}$ NMP was first prepared via magnetic stirring for $24 \mathrm{~h}$ at room temperature. Then, $15.0 \mathrm{~g}$ of $\mathrm{p}-\mathrm{HdA}$ and $16.0 \mathrm{~g}$ of NMP were added into the mixture, subsequently sonicated for $60 \mathrm{~min}$, and continuously mixed for $24 \mathrm{~h}$. After homogenization, the mixture was poured into a $50 \mathrm{~mL}$ disposable KOVAX syringe (Henke Sass Wolf $\mathrm{GmbH}$, Tuttlingen, Germany) and extruded using a KDS230 syringe pump (KD Scientific Inc., Holliston, MA, USA) with a flow rate of $1 \mathrm{~mL} / \mathrm{min}$. The spherical b-HdA was formed when the mixture was added dropwise into deionized water (DIW) and cured for $1 \mathrm{~h}$. After the hardening stage, we rinsed the b-HdA three times with DIW and then dried it overnight at room temperature. Finally, the produced b-HdA was calcinated at $550{ }^{\circ} \mathrm{C}$ for $2 \mathrm{~h}$ to remove the PVB and residual organic compounds.

\subsection{Adsorption Experiments}

The adsorption equilibrium was carried out with $300 \mathrm{~mL}$ glass bottles containing $200 \mathrm{~mL}$ of $\mathrm{Co}$ (II) solution $(0-10 \mathrm{mg} / \mathrm{L})$ at $\mathrm{pH} 7.0 \pm 0.1$. After $0.1 \mathrm{~g}$ of either $\mathrm{p}-\mathrm{HdA}$ or b-HdA was added into each bottle, the bottles were placed in a shaking incubator (WIS-20, DAIHAN Scientific Co., Ltd., Seoul, Korea) at 150 rpm under different temperatures (293, 303 , and $313 \mathrm{~K}$ ) for $30 \mathrm{~h}$ to ensure that saturated adsorption took place. The adsorption kinetic studies were performed by adding $0.1 \mathrm{~g}$ of adsorbents to $40 \mathrm{~mL}$ of a Co(II) solution $(10 \mathrm{mg} / \mathrm{L})$ and having the experiment proceed for $30 \mathrm{~h}$ under $293 \mathrm{~K}$. The competitive adsorption of $\mathrm{Co}(\mathrm{II})$ in the presence of $\mathrm{Ni}(\mathrm{II}), \mathrm{Sr}(\mathrm{II}), \mathrm{Cs}(\mathrm{I})$, or $\mathrm{U}(\mathrm{VI})$ was investigated by introducing $0.05 \mathrm{~g}$ of absorbents to $40 \mathrm{~mL}$ of adsorbate mixtures with different initial concentrations $(0.1,1.0$. and $5.0 \mathrm{mg} / \mathrm{L})$. All samples were taken at predetermined intervals, filtered through a $0.22 \mu \mathrm{m}$ polyvinylidene fluoride (PVDF) syringe filter (Hyundai Micro), and acidified to $\mathrm{pH} 3.0$ using concentrated $\mathrm{HNO}_{3}$. An inductively coupled plasma mass spectrometry (ICP-MS) method (Agilent ICP-MS 7700S, Agilent, Santa Clara, CA, USA) was used to analyze the concentrations of the radionuclides.

The adsorption capacity of radionuclides $\left(q_{e}(\mathrm{mg} / \mathrm{g})\right)$ was calculated using the following mass balance equation [28]:

$$
q_{e}=\frac{\left(C_{o}-C_{e}\right) V}{m}
$$

where $C_{o}$ and $C_{e}(\mathrm{mg} / \mathrm{L})$ are the initial and equilibrium concentrations of the adsorbate, respectively, $V(\mathrm{~L})$ is the volume of the adsorbate solution, and $m(\mathrm{~g})$ is the mass of the b-HdA used.

\subsection{Analytical Methods}

\subsubsection{Material Characterization}

The surface morphology of the prepared b-HdA was acquired using a field emission scanning electron microscope (FESEM, SU8230, Hitachi Corp., Tokyo, Japan) equipped with an energy-dispersive X-ray spectroscope (EDX). The Brunauer-Emmett-Teller (BET) specific area, the Barrett-Joyner-Halenda $(\mathrm{BJH})$ pore size, and the pore volume were measured using a BELSORP MAX surface analyzer (MicrotracBEL Corp., Tokyo, Japan). The $X$-ray diffraction (XRD) of the adsorbents were examined using a RIGAKU diffractometer (D/MAX-2500, Tokyo, Japan) scanned over the range of $2 \theta=5-80^{\circ}$ with a $\mathrm{Cu} \mathrm{K} \alpha$ radiation source $(\lambda=1.5418 \AA)$. The $\mathrm{pH}$ of the point of zero charge (pHpzc) of the b-HdA was checked using the $\mathrm{pH}$ drift method [29]. Briefly, $0.15 \mathrm{~g}$ of the b-HdA were embedded in a $40 \mathrm{~mL}$ solution with $\mathrm{pH}$ 's ranging from 2 to 11 . After $24 \mathrm{~h}$ of shaking at $150 \mathrm{rpm}$, the $\mathrm{pH}$ stabilized and we measured the final $\mathrm{pH}$. The $\mathrm{pHpzc}$ was determined as the point at which the initial $\mathrm{pH}$ and final $\mathrm{pH}$ values were equal. 


\subsubsection{Adsorption Data Analysis}

In this presented work, the experimental equilibrium data were analyzed using four well-known isothermal models, namely, the Langmuir, Freundlich, Sips, and Tempkin isotherm models $[9,30]$. The mathematical expressions of these models are given in Table S1. To determine the possible nature of the adsorption process, the thermodynamic parameters were defined using equations in Table S2. A more detailed explanation can be found in our previous publication [31]. The experimental kinetic data were evaluated using the pseudo-first-order, pseudo-second-order, intra-particle diffusion, and three-stage models to determine the type of mechanism and potential rate-controlling step of the adsorption processes $[9,32,33]$. These kinetic equations are presented in Table S3.

\section{Results and Discussion}

\subsection{Physico-Chemical Properties of the Prepared $b-H d A$}

The nitrogen adsorption-desorption isotherms of the p-HdA and b-HdA are presented in Figure 1a. Both the p-HdA and b-HdA exhibited type IV isotherms with type $\mathrm{H}_{3}$ hysteresis loops, suggesting that the materials had mesoporous structures with the aggregates of particles forming slit-like pores [34,35]. The BJH pore size distribution curves illustrated in Figure $1 \mathrm{~b}$ confirmed that mesopores were predominant for both materials. It can also be seen from Figure $1 b$ that the $\mathrm{p}-\mathrm{HdA}$ had a broader pore size distribution compared to the HdA pellets.

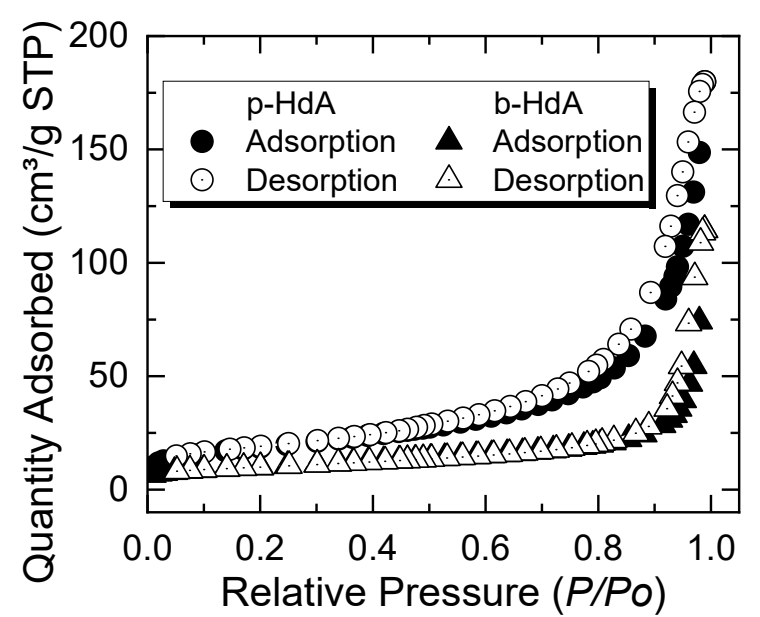

(a)

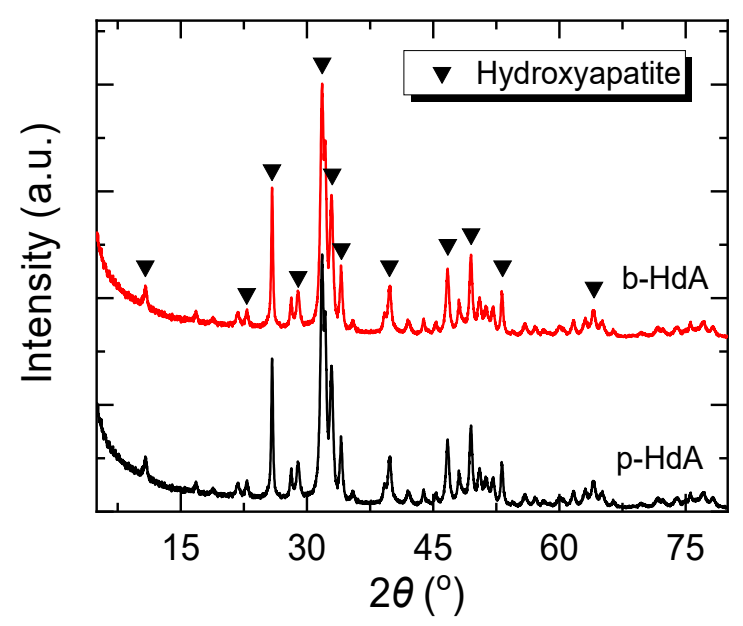

(c)

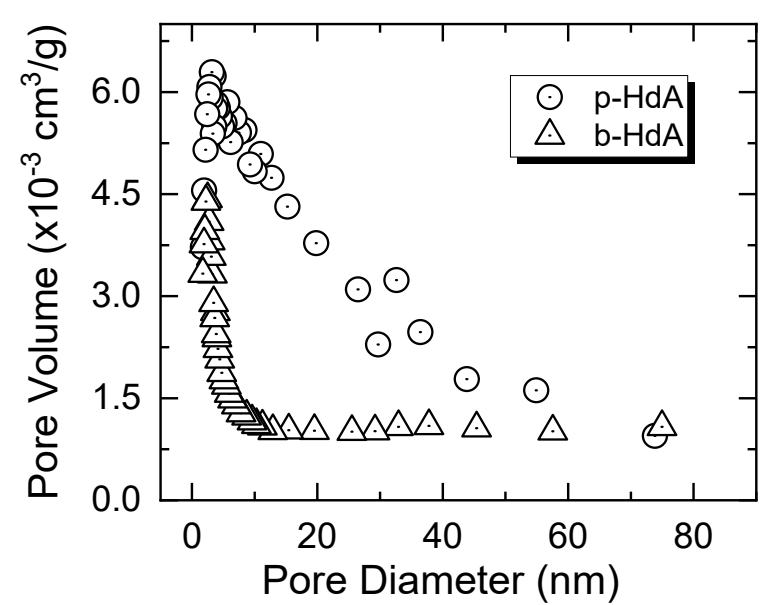

(b)

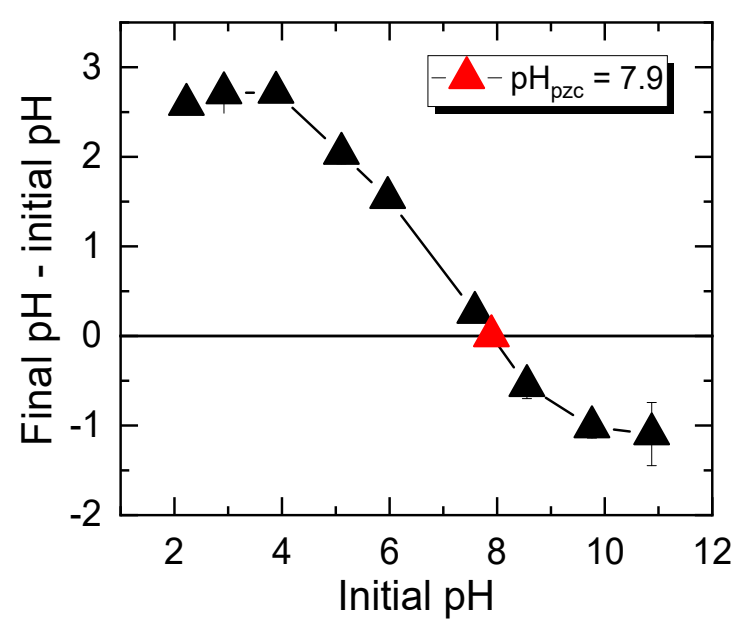

(d)

Figure 1. Typical nitrogen adsorption-desorption isotherms (a), pore size distribution (b), X-ray diffraction (XRD) patterns of the powdered $\mathrm{HdA}(\mathrm{p}-\mathrm{HdA})$ and the porous bead form of $\mathrm{HdA}(\mathrm{b}-\mathrm{HdA})(\mathbf{c})$, and $\mathrm{pH}_{\mathrm{pzc}}$ of b-HdA (d). 
The mean pore diameters of $\mathrm{p}-\mathrm{HdA}$ and b-HdA were $16.22 \mathrm{~nm}$ and $22.73 \mathrm{~nm}$, respectively, as presented in Table 1. The BET specific surface area of the b-HdA was half that of the p-HdA, which could be foreseen due to the effect of particle size on the BET specific surface area [36].

Table 1. Elemental compositions of the p-HdA and b-HdA.

\begin{tabular}{|c|c|c|c|c|}
\hline Material & BET Surface Area $\left(\mathrm{m}^{2} / \mathrm{g}\right)$ & Pore Volume $\left(\mathrm{cm}^{3} / \mathrm{g}\right)^{a}$ & Mean Pore Size (nm) & Adsorption Capacity of Co(II) (mg/g) \\
\hline p-HdA & 67.14 & 0.27 & 16.22 & 14.07 \\
\hline b-HdA & 34.91 & 0.18 & 22.73 & 7.73 \\
\hline
\end{tabular}

${ }^{\text {a }}$ Pore volume was calculated at $P / P_{0}=0.990 ;{ }^{b}$ Obtained with a $10 \mathrm{mg} / \mathrm{L}$ initial concentration of Co(II) and the temperature at $293 \mathrm{~K}$. BET: Brunauer-Emmett-Teller.

The XRD patterns of the p-HdA and b-HdA presented in Figure 1c matched well with the standard patterns of the hexagonal crystal hydroxyapatite compiled by the International Centre for Diffraction Data (ICDD) card no. 01-074-0565 and 01-082-2956, respectively. The sharp, narrow, and well-resolved diffraction peaks observed in Figure 1c corresponded to the Miler indices of 100, 002, 210, 211, 112, 300, 202, 130, 222, 132, 213, 321, and 004, respectively, confirming the crystallized structure of the materials [37,38]. Furthermore, no additional peaks were found in the diffraction pattern of the b-HdA, indicating that hydroxyapatite was the only phase and PVB completely decomposed into volatile products at $550{ }^{\circ} \mathrm{C}$ [39]. Furthermore, a slightly higher intensity of the diffraction peaks was obtained for b-HdA compared to that of $\mathrm{p}-\mathrm{HdA}$, which might have resulted from the fact that the sintering process improved the crystallinity of the material [40].

Figure $1 \mathrm{~d}$ shows that the $\mathrm{pH}_{\mathrm{pzc}}$ of the $\mathrm{b}-\mathrm{HdA}$ was 7.9 , which was similar to the precursor-HdA powder and other previous studies [38,41,42]. However, it is noteworthy to mention that the $\mathrm{pH}_{\mathrm{pzc}}$ of the $\mathrm{HdA}$ can fall in a wide range (4.3-9.2) depending on the synthesized method, HdA precursor, stoichiometry and purity, experimental conditions, and techniques $[21,43]$. It has also been reported that the $\mathrm{pH}_{\mathrm{pzc}}$ value of the HdA correlates proportionally with the quantity of $\mathrm{Ca}$ in the HdA surface [44].

Figure $2 \mathrm{a}, \mathrm{b}$ depicts the photographs of the $\mathrm{p}-\mathrm{HdA}$ and $\mathrm{b}-\mathrm{HdA}$, respectively. The prepared b-HdA was typically spherical with an approximate diameter of $2.0 \mathrm{~mm}$. The surface morphology of the $\mathrm{p}-\mathrm{HdA}$ and $\mathrm{b}-\mathrm{HdA}$ were recorded using SEM analysis, as shown in Figure $2 \mathrm{c}, \mathrm{d}$. The b-HdA was a rough and multiporous surface. Only the constitutive elements of $\mathrm{HdA}(\mathrm{O}, \mathrm{Ca}$, and $\mathrm{P})$ were detected according to the EDX results (data not shown), which were consistent with the XRD results obtained above.

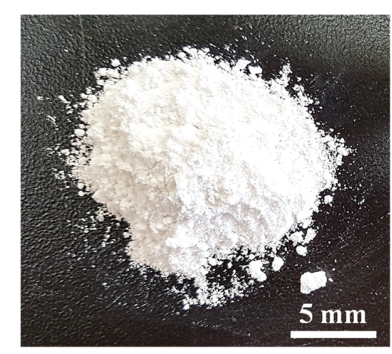

(a)

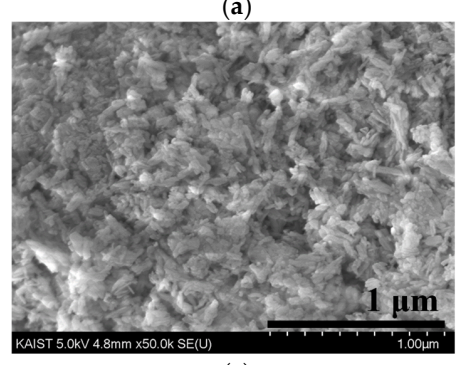

(c)

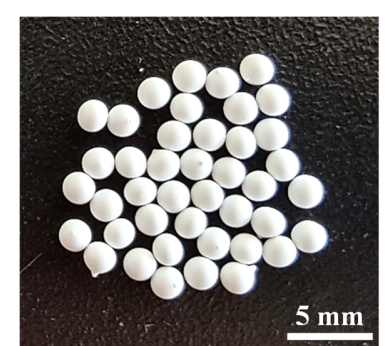

(b)

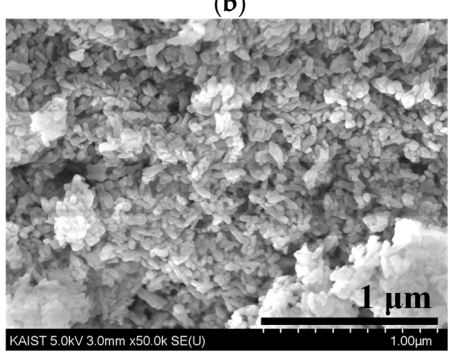

(d)

Figure 2. Microscopic and SEM images of p-HdA (a,c) and b-HdA (b,d). 


\subsection{Adsorption Isotherms}

The adsorption parameters that were attained by fitting the equilibrium adsorption data with the four selected isotherm models are summarized in Table 2. The regression coefficient $\left(R^{2}\right)$ values of the four adsorption isotherms in Table 2 show that the Sips, Freundlich, and Langmuir models provided better fits than the Tempkin model. Among these models, the Sips model was adapted to explain the uptake behavior of Co(II) onto the b-HdA.

Table 2. Summary of the adsorption model parameters for $\mathrm{Co}(\mathrm{II})$ onto the b-HdA at various temperatures.

\begin{tabular}{cccccc}
\hline \multirow{2}{*}{ Isotherms } & \multicolumn{2}{c}{ Parameters } & \multicolumn{3}{c}{ Temperature (K) } \\
\cline { 3 - 5 } & \multicolumn{2}{c}{} & $\mathbf{2 9 3}$ & $\mathbf{3 0 3}$ & $\mathbf{3 1 3}$ \\
\hline \multirow{2}{*}{ Langmuir } & $q_{\max }$ & $(\mathrm{mg} / \mathrm{g})$ & 4.91 & 6.10 & 6.41 \\
& $K$ & $(\mathrm{~L} / \mathrm{mg})$ & 0.40 & 0.44 & 1.12 \\
& $R^{2}$ & & 0.99 & 0.99 & 0.98 \\
\hline \multirow{2}{*}{ Freundlich } & $K_{F}$ & $(\mathrm{mg} / \mathrm{g}$ & 1.35 & 1.76 & 2.84 \\
& $1 / n$ & & 0.51 & 0.50 & 0.41 \\
& $R^{2}$ & & 0.99 & 0.99 & 0.99 \\
\hline \multirow{2}{*}{ Sips } & $q_{\max }$ & $(\mathrm{mg} / \mathrm{g})$ & 7.73 & 10.38 & 11.35 \\
& $K_{S}$ & $(1 / \mathrm{mg})$ & 0.20 & 0.19 & 0.42 \\
& $n_{S}$ & & 0.74 & 0.68 & 0.61 \\
& $R^{2}$ & & 0.99 & 0.99 & 0.99 \\
\hline \multirow{2}{*}{ Tempkin } & $b_{T}$ & $(\mathrm{~kJ} / \mathrm{mol})$ & 3.69 & 3.11 & 2.89 \\
& $A_{T}$ & $(\mathrm{~L} / \mathrm{mg})$ & 16.20 & 18.88 & 48.53 \\
& $R^{2}$ & & 0.88 & 0.88 & 0.92 \\
\hline
\end{tabular}

Figure 3 presents the equilibrium adsorption data fitted using the Sips adsorption model at different experimental temperatures. The maximum adsorption capacity $\left(q_{\max }\right)$ of the b-HdA that was calculated from the Sips isotherm for $\mathrm{Co}$ (II) ions at $293 \mathrm{~K}$ was $7.73 \mathrm{mg} / \mathrm{g}$, which was about half that for p-HdA $(14.07 \mathrm{mg} / \mathrm{g})$ due to b-HdA's smaller BET specific surface area. The Sips model was developed from the basis of the Freundlich and Langmuir models, which are described by the dimensionless heterogeneity factor $n_{s}$. At values of $n_{s}$ close to (or exactly) 1 , the Sips isotherm approaches the Langmuir isotherm, which suggests homogeneous adsorption. From Table 2, it was found that the value of $n_{s}$ was much lower than 1 for all investigated temperatures, indicating that the b-HdA had an energetically heterogeneous surface [9]. It is believed that this heterogeneity was caused by the distinct binding sites present on the HdA surface, i.e., positively charged calcium ions and negatively charged hydroxyl, together with phosphate groups [1,20,44]. Consequently, different possible adsorption mechanisms can take place during the adsorption process, i.e., ion exchange and dissolution-precipitation according to Equations (2)-(4) $[6,20]$.

$$
\begin{gathered}
\mathrm{Ca}_{10}\left(\mathrm{PO}_{4}\right)_{6}(\mathrm{OH})_{2}+2 \mathrm{Co}^{2+} \rightarrow \mathrm{Ca}_{8} \mathrm{Co}_{2}\left(\mathrm{PO}_{4}\right)_{6}(\mathrm{OH})_{2}+2 \mathrm{Ca}^{2+}, \\
\mathrm{Ca}_{10}\left(\mathrm{PO}_{4}\right)_{6}(\mathrm{OH})_{2}+14 \mathrm{H}^{+} \rightarrow 10 \mathrm{Ca}^{2+}+6 \mathrm{H}_{2} \mathrm{PO}_{4}{ }^{-}+2 \mathrm{H}_{2} \mathrm{O}, \\
10 \mathrm{Co}^{2+}+6 \mathrm{H}_{2} \mathrm{PO}_{4}^{-}+2 \mathrm{H}_{2} \mathrm{O} \rightarrow \mathrm{Co}_{10}\left(\mathrm{PO}_{4}\right)_{6}(\mathrm{OH})_{2}+14 \mathrm{H}^{+} .
\end{gathered}
$$

It is noteworthy that the ion exchange with $\mathrm{Ca}$ (II) ions in the HdA lattice was rapid and more favorably took place over the dissolution-precipitation process when the adsorbates were divalent ions [12,43]. 


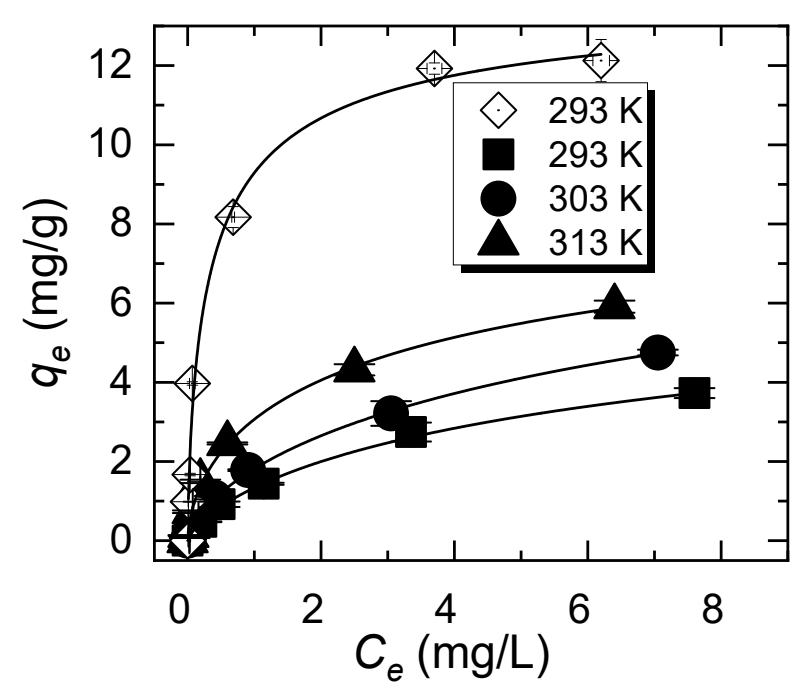

Figure 3. Adsorption isotherm of $\mathrm{Co}$ (II) for p-HdA (open symbol) and b-HdA (solid symbols) at various temperatures. Note that the lines show the best fits of the Sips model.

The comparison of adsorption capacities of $\mathrm{Co}(\mathrm{II})$ using various adsorbents is presented in Table 3. It can be seen that the adsorption capacity of Co(II) by the b-HdA fabricated in this study was lower than that of other HdA-based adsorbents due to its larger size. Nevertheless, the b-HdA exhibited higher adsorption capacity than other granular adsorbents, such as activated carbon [45] and clinoptilolite [46]. This finding suggested that the b-HdA can serve as a competent adsorbent for practical applications in the removal of $\mathrm{Co}$ (II) from contaminated water.

Table 3. Comparison of the adsorption capacities of $\mathrm{Co}(\mathrm{II})$ using various absorbents.

\begin{tabular}{ccccccc}
\hline Adsorbent & BET Surface Area $\left(\mathbf{m}^{\mathbf{2}} \mathbf{g}\right)$ & $\mathbf{p H}$ & Temperature $\mathbf{( K )}$ & $\left.\boldsymbol{q}_{\text {max }} \mathbf{( m g} / \mathbf{g}\right)$ & Reference \\
\hline Eggshell p-HdA & 11.84 & 4.5 & 398 & 3.41 & 14.0 & {$[1]$} \\
Commercial p-HdA & 21.0 & 6.0 & 298 & 62.0 & {$[6]$} \\
Biogenic p-HdA & 94.0 & 6.0 & 298 & 20.9 & {$[6]$} \\
Synthetic p-HdA & 67.0 & 5.0 & 293 & 303 & {$[19]$} \\
Synthetic p-HdA & 100.5 & 4.0 & 303 & 2.4 & {$[20]$} \\
Activated carbon & 603.0 & 6.0 & 298 & 19 & {$[45]$} \\
Clinoptilolite & 20.0 & 5.5 & 293 & 7.07 & This study \\
p-HdA & 67.14 & 7.0 & 293 & & This study \\
b-HdA & 34.91 & 7.0 & & &
\end{tabular}

In addition, an increase in the adsorption capacity was observed with an increase in the experimental temperature from 293 to $313 \mathrm{~K}$. This implies that the adsorption process was endothermal in nature and for the analysis that follows.

\subsection{Thermodynamic Study}

Thermodynamic studies were performed to determine the nature of the adsorption processes. In this work, the thermodynamic equilibrium constants $\left(K_{0}\right)$ were calculated via $\ln \left(K_{0}\right)$ at different investigated temperatures $(293,303$, and $313 \mathrm{~K})$ by plotting $\ln \left(C_{s} / C_{e}\right)$ versus $C_{S}$ and extrapolating $C_{s}$ to zero, as illustrated in Figure 4a [30]. The standard enthalpy change $\left(\Delta H^{0}\right)$ and the standard entropy change $\left(\Delta S^{0}\right)$ of the adsorption process were respectively obtained from the slope $\left(-\Delta H^{0} / R\right)$ and the intercept $\left(\Delta S^{0} / R\right)$ of the plots of $\ln \left(K_{0}\right)$ as a function of $1 / T$, as shown in Figure $4 \mathrm{~b}$. 


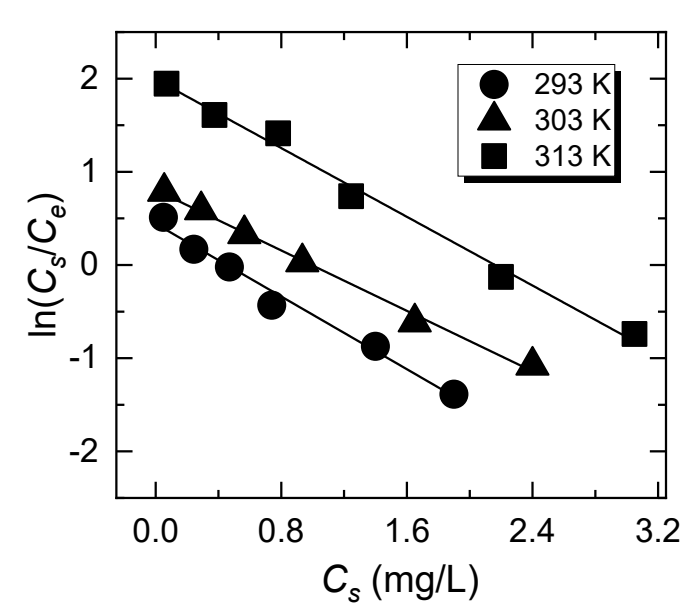

(a)

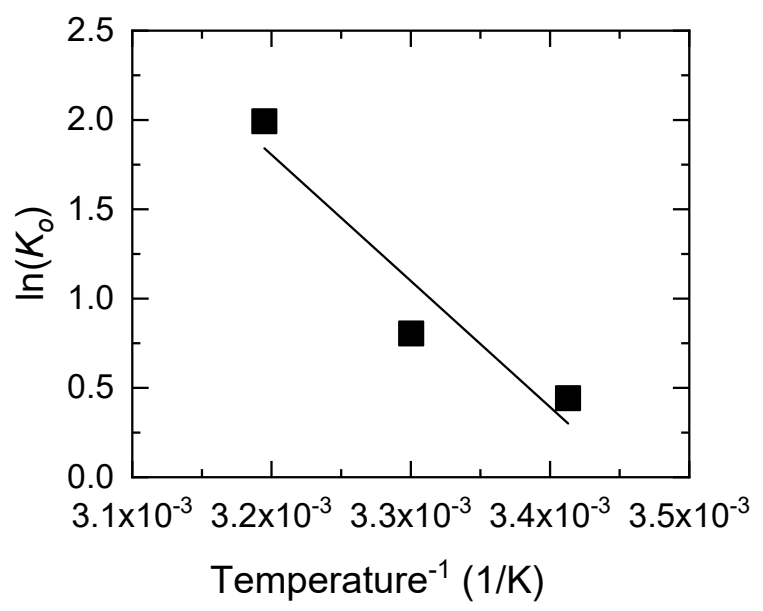

(b)

Figure 4. The fitting results of thermodynamic analysis: (a) plots of $\ln \left(C_{s} / C_{e}\right)$ versus $C_{s}$ at different experimental temperatures and (b) $\ln \left(K_{0}\right)$ versus $1 / T$.

The calculated parameters are summarized in Table 4 . The positive value of enthalpy $\Delta H^{0}$ confirmed the endothermic nature of the adsorption process. As a result, the adsorption of $\mathrm{Co}$ (II) onto the b-HdA was favorable at high temperatures [31]. Furthermore, the positive value of entropy $\Delta S^{0}$ indicates that the randomness at the b-HdA and solution interface increased during the adsorption process due to the release of the solvated water molecules present on the surface of the b-HdA [38]. Furthermore, the negative values of the standard Gibbs free energy change $\left(\Delta G^{0}\right)$ at all investigated temperatures indicated that the adsorption of $\mathrm{Co}(\mathrm{II})$ ions onto the b-HdA was thermodynamically favorable and spontaneous [38].

Table 4. Thermodynamic parameters of Co(II) during the adsorption onto b-HdA.

\begin{tabular}{ccccc}
\hline $\begin{array}{c}\text { Temperature } \\
(\mathbf{K})\end{array}$ & $\boldsymbol{K}_{\mathbf{0}}$ & $\begin{array}{c}\Delta G^{\mathbf{0}} \\
\mathbf{( k J / m o l )}\end{array}$ & $\begin{array}{c}\Delta \boldsymbol{S}^{\mathbf{0}} \\
\mathbf{( k J / m o l} \cdot \mathbf{K})\end{array}$ & $\begin{array}{c}\Delta \boldsymbol{H}^{\mathbf{0}} \\
\mathbf{( k J / m o l )}\end{array}$ \\
\hline 293 & 1.56 & -1.08 & & \\
303 & 2.24 & -2.03 & 0.20 & 58.72 \\
313 & 7.33 & -5.18 & & \\
\hline
\end{tabular}

\subsection{Adsorption Kinetics}

Figure 5a elucidates the fitting of the pseudo-second-order and three-stage kinetic models with the experimental kinetics data for the adsorption of Co(II) onto the b-HdA. The correlation coefficients $\left(R^{2}\right)$ in Table 5 show a better fit to the pseudo-second-order than the pseudo-first-order model, revealing that the pseudo-second-order model was more suitable for describing the kinetic mechanisms of $\mathrm{Co}$ (II) adsorption onto the b-HdA. Hence, the $\mathrm{Co}$ (II) adsorbed onto the adsorbent might have been controlled by a chemisorption step. Furthermore, the adsorption behavior of $\mathrm{Co}$ (II) on the exterior and interior adsorptive sites of the HdA pellets was revealed through the three-stage kinetic model. The threestage model considers three different adsorption stages, including the first (sharp) portion reflecting external mass transfer, the second (gradual) portion representing the internal surface adsorption (intraparticle diffusion), and the third (constant) portion denoting the equilibrium stage $[9,32]$. It can be seen from Figure 5 a that the $C_{t} / C_{o}$ values achieved from the calculations of the three-stage model were very close to the experimental data. In addition, a significantly lower instantaneous adsorption portion $\left(\xi_{1}\right)$ compared to the interior adsorption portion $\left(\xi_{2}\right)$ indicates that a major part of the adsorption occurred on the internal adsorptive sites of the b-HdA, as presented in Table 5 [32]. Consequently, the mechanism controlling the process might have been intraparticle diffusion [32,43]. 
Furthermore, the value of $\xi_{1}$ was very small, suggesting that the external surface adsorption of $\mathrm{Co}$ (II) ions occurred rapidly and that the adsorption process quickly progressed to the intraparticle diffusion stage [9].

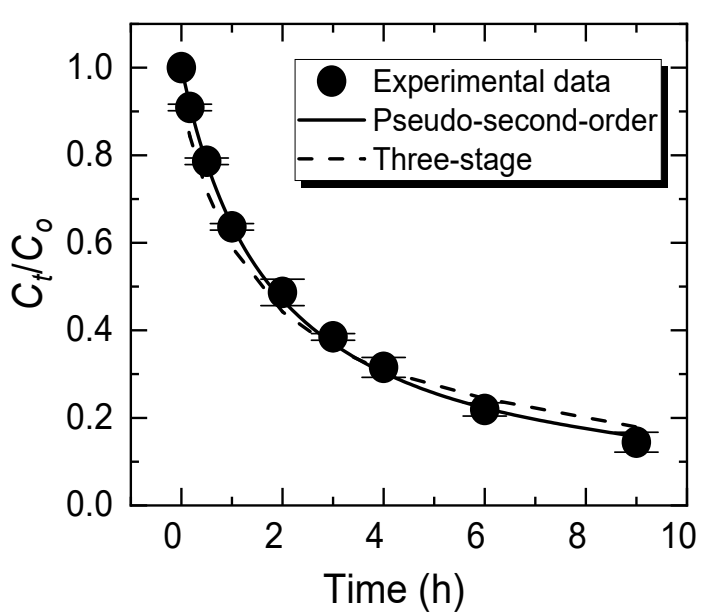

(a)

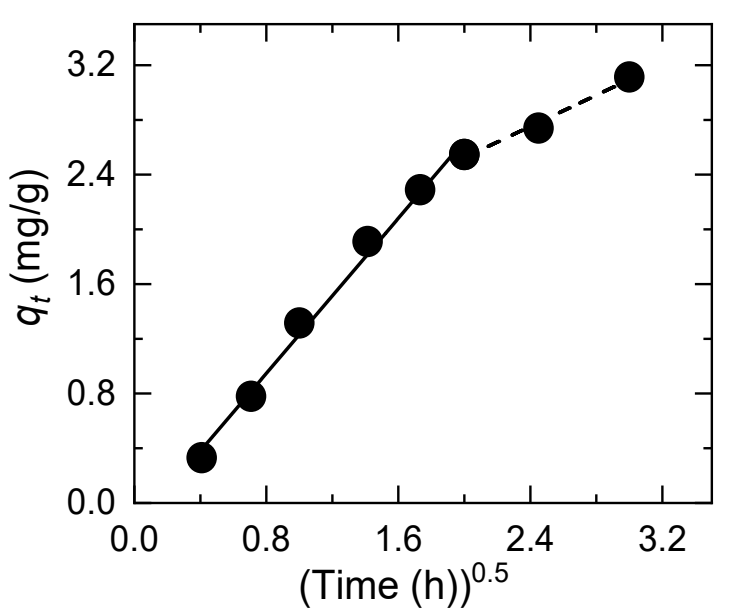

(b)

Figure 5. Adsorption kinetic data fitted to (a) pseudo-second-order and three-stage models and (b) an intra-particle diffusion model for Co(II) adsorption onto the b-HdA at $293 \mathrm{~K}$.

Table 5. Summary of the kinetic model parameters for Co(II) adsorption onto the b-HdA at $293 \mathrm{~K}$.

\begin{tabular}{cccc}
\hline Models & \multicolumn{2}{c}{ Parameters } & Value \\
\hline \multirow{3}{*}{ Pseudo-first-order } & $q_{e}$ & $(\mathrm{mg} / \mathrm{g})$ & 2.87 \\
& $k_{1}$ & $(1 / \mathrm{h})$ & 0.13 \\
& $R^{2}$ & & 0.98 \\
\hline \multirow{3}{*}{ Pseudo-second-order } & $q_{e}$ & $(\mathrm{mg} / \mathrm{g})$ & 3.69 \\
& $k_{2}$ & $(\mathrm{~g} / \mathrm{mg} \mathrm{h})$ & 0.15 \\
& $R^{2}$ & & 0.99 \\
\hline Three-stage & $\xi_{1}$ & & 0.07 \\
& $\xi_{2}$ & $(1 / \mathrm{h})$ & 0.93 \\
& $\alpha$ & & 0.59 \\
Intra-particle & $\beta$ & & 0.89 \\
diffusion & $\gamma$ & $\left(\mathrm{mg} / \mathrm{g} \mathrm{h}^{0.5}\right)$ & 0.09 \\
\hline
\end{tabular}

Figure $5 \mathrm{~b}$ shows the graph of $q_{t}$ versus $t^{0.5}$, which fits the experimental data with the intraparticle diffusion model. The plot presents a linearized section (i.e., red dotted line) during the second (gradual) portion of the adsorption process, which indicates that intraparticle diffusion took place in the rate-limiting step. This result is consistent with the data obtained from the three-stage kinetic model (discussed above). However, the plot did not pass through the origin $(I \neq 0)$; thus, intraparticle diffusion was not the sole rate-controlling step of the adsorption process [30]. It is noteworthy that two linearity fractions with different slopes corresponding to different stages in the adsorption process were observed in Figure 5b, implying that the multi-kinetic stage might have governed the adsorption of $\mathrm{Co}(\mathrm{II})$ onto the b-HdA.

\subsection{Comparability and Selectivity of the b-HdA in a Multi-Ionic System}

Several radionuclide ions, such as $\mathrm{Ni}(\mathrm{II}), \mathrm{Sr}(\mathrm{II}), \mathrm{Cs}(\mathrm{I})$, and $\mathrm{U}(\mathrm{VI})$, have frequently been detected in groundwater and wastewater, which might significantly affect the adsorption behavior of $\mathrm{Co}(\mathrm{II})$ [3]. We observed that the removal efficiencies of $\mathrm{Co}(\mathrm{II})$ decreased consid- 
erably in the multi-ionic systems compared to those in the single systems (data not shown), which could be attributed to competing effects. Furthermore, the selective order in the adsorption of these radionuclides on the b-HdA was $\mathrm{U}(\mathrm{VI})>\mathrm{Co}(\mathrm{II})>\mathrm{Ni}(\mathrm{II})>\mathrm{Sr}(\mathrm{II})>\mathrm{Cs}(\mathrm{I})$, as illustrated in Figure 6a,b. Research has shown that the absorption preference is affected by various characteristics of the adsorbates, such as ionic valence, ionic radius, hydration radius, electronegativity, hydration enthalpy, and charge density $[6,40,44]$. Generally, the adsorptive sites are preferentially occupied by ions with higher electronegativity, bigger ionic radius and valence, and smaller hydration radius [12]. Furthermore, ions with a higher hydration enthalpy prefer the solution phase, where it may satisfy its hydration requirements. In contrast, ions with a lower hydration enthalpy prefer the adsorbent phase [12]. In this respect, the characteristic parameters of the investigated radionuclides ions are presented in Table S4. It can be observed that even the trends could not provide a consistent rule for examined radionuclides' selectivities for the b-HdA. Nevertheless, it is noteworthy that the selective order of examined ions only coincided with the order trend of charge density, which was $\mathrm{U}(\mathrm{VI})>\mathrm{Co}(\mathrm{II})>\mathrm{Ni}(\mathrm{II})>\mathrm{Sr}(\mathrm{II})>\mathrm{Cs}(\mathrm{I})$, suggesting that the adsorption affinity might more strongly depend on the charge density of ions than other characteristics. It was reported that ions with a larger charge density are capable of substituting $\mathrm{Ca}(\mathrm{II})$ ions on the $\mathrm{HdA}$ surface more easily and quickly than others [3,19,47]. Considering that ion exchange takes place as the main adsorption mechanism, this postulation is a reasonable way to interpret the selectivity of the adsorption process in this work. Our results are consistent with previous studies using hydroxyapatite-based materials as adsorbents for the uptake of metal ions $[3,17,48]$.

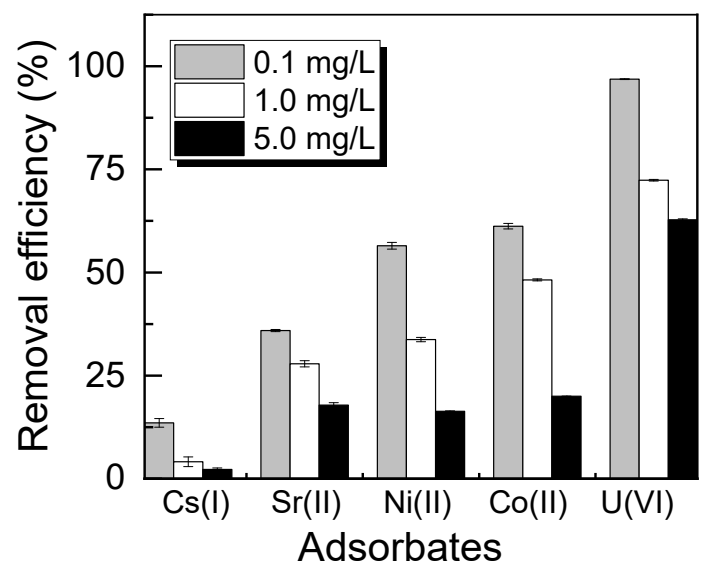

(a)

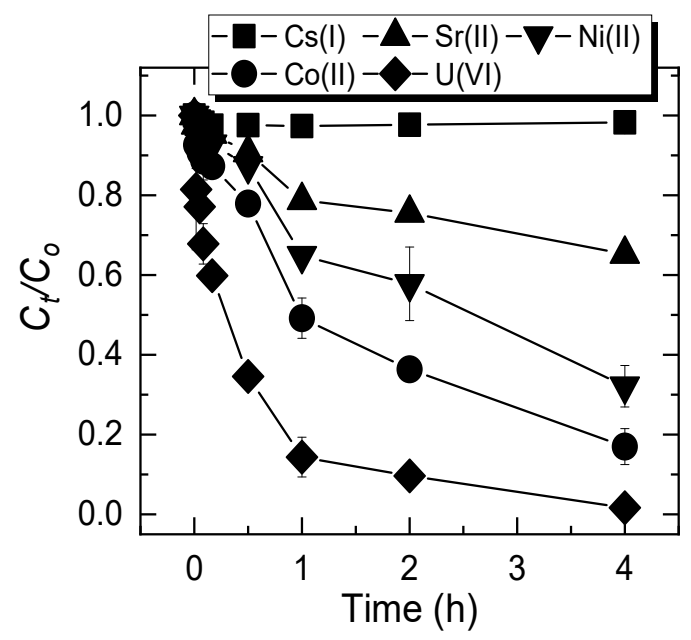

(b)

Figure 6. Competitive adsorption behavior of $\mathrm{Co}(\mathrm{II})$ : (a) changes in removal efficiencies at various initial concentrations and (b) adsorption kinetics of various radionuclides at the initial concentration of $0.1 \mathrm{mg} / \mathrm{L}$ at $293 \mathrm{~K}$.

\section{Conclusions}

In this work, spherical b-HdA with an approximate diameter of $2.0 \mathrm{~mm}$ was successfully prepared via a sintering process. The prepared b-HdA had a well-crystallized and mesoporous structure with a BET specific surface area of $34.91 \mathrm{~m}^{2} / \mathrm{g}$ and a maximum specific adsorption of $7.73 \mathrm{mg} / \mathrm{g}$ b-HdA for $\mathrm{Co}(\mathrm{II})$ at $293 \mathrm{~K}$. The adsorption behaviors and mechanisms of $\mathrm{Co}$ (II) ions onto the b-HdA could be explained well using the Sips isotherm model and the pseudo-second-kinetic model, indicating the heterogeneous surface property of b-HdA. The adsorption capacity was increased with an increase in temperature, along with the thermodynamic parameters, indicating that the adsorption of Co(II) onto the b-HdA was thermodynamically favorable and spontaneous. Furthermore, intraparticle diffusion controlled the uptake of $\mathrm{Co}$ (II) onto the b-HdA as a rate-limiting step. The selective order of the b-HdA in a mixture of radionuclides was $\mathrm{U}(\mathrm{VI})>\mathrm{Co}(\mathrm{II})>\mathrm{Ni}(\mathrm{II})>$ 
$\mathrm{Sr}(\mathrm{II})>\mathrm{Cs}(\mathrm{I})$ due to the impact of electronegativity with $\mathrm{Ca}^{2+}$ ions in the HdA structures. The easy-to-fabricate b-HdA can be employed as an effective industrial absorbent in the continuous-flow adsorption columns for the control of heavy metallic radionuclides from aqueous environments.

Supplementary Materials: The following are available online at https://www.mdpi.com/2076-341 7/11/4/1746/s1, Table S1: Adsorption isotherm models, Table S2: Thermodynamic analysis, Table S3: Adsorption kinetic models, Table S4: Chemical properties of selected radionuclides.

Author Contributions: Conceptualization, S.K.; methodology, T.N.T.; validation, S.K.; formal analysis, T.N.T. and J.K.; investigation, J.-S.P. and Y.C.; data curation, T.N.T.; writing-original draft preparation, T.N.T.; writing - review and editing, S.K.; supervision, S.K.; project administration, S.K.; funding acquisition, J.H., S.O. and S.K. All authors have read and agreed to the published version of the manuscript.

Funding: This research was financially supported by the Hyundai Engineering and Construction (HDEC) project.

Institutional Review Board Statement: Not applicable.

Informed Consent Statement: Not applicable.

Data Availability Statement: Data are contained within the article and the Supplementary Materials.

Conflicts of Interest: The authors declare no conflict of interest. The funders had no role in the design of the study; in the collection, analyses, or interpretation of data; in the writing of the manuscript, or in the decision to publish the results.

\section{References}

1. Imam, D.M.; Moussa, S.I.; Attallah, M.F. Sorption behavior of some radionuclides using prepared adsorbent of hydroxyapatite from biomass waste material. J. Radioanal. Nucl. Chem. 2019, 319, 997-1012. [CrossRef]

2. Smičiklas, I.; Sljivic-Ivanovic, M. Radioactive Contamination of the Soil: Assessments of Pollutants Mobility with Implication to Remediation Strategies. In Soil Contamination-Current Consequences and Further Solutions, 1st ed.; Laramendy, M.L., Soloneski, S., Eds.; IntechOpen: London, UK, 2016.

3. Venkatesan, S.; Hassan, M.U.; Ryu, H.J. Adsorption and immobilization of radioactive ionic-corrosion-products using magnetic hydroxyapatite and cold-sintering for nuclear waste management applications. J. Nucl. Mater. 2019, 514, 40-49. [CrossRef]

4. Leyssens, L.; Vinck, B.; Van Der Straeten, C.; Wuyts, F.; Maes, L. Cobalt toxicity in humans-A review of the potential sources and systemic health effects. Toxicology 2017, 387, 43-56. [CrossRef] [PubMed]

5. El-Zakla, T.; Yakout, S.; Rizk, M.; Lasheen, Y.; Gad, H. Removal of Cobalt-60 and Caesium-134 Ions from Contaminated Solutions by Sorption Using Activated Carbon. Adsorp. Sci. Technol. 2011, 29, 331-344. [CrossRef]

6. Handley-Sidhu, S.; Mullan, T.K.; Grail, Q.; Albadarneh, M.; Ohnuki, T.; Macaskie, L.E. Influence of pH, competing ions, and salinity on the sorption of strontium and cobalt onto biogenic hydroxyapatite. Sci. Rep. 2016, 6, 23361. [CrossRef] [PubMed]

7. Alkhadra, M.A.; Conforti, K.M.; Gao, T.; Tian, H.; Bazant, M.Z. Continuous Separation of Radionuclides from Contaminated Water by Shock Electrodialysis. Environ. Sci. Technol. 2020, 54, 527-536. [CrossRef]

8. Bolisetty, S.; Coray, N.M.; Palika, A.; Prenosil, G.A.; Mezzenga, R. Amyloid hybrid membranes for removal of clinical and nuclear radioactive wastewater. Environ. Sci. Wat. Res. 2020, 6, 3249-3254. [CrossRef]

9. Tran, T.N.; Kim, D.-G.; Ko, S.-O. Adsorption Mechanisms of Manganese (II) Ions onto Acid-treated Activated Carbon. KSCE J. Civ. Eng. 2018, 22, 3772-3782. [CrossRef]

10. Do, Q.C.; Kim, M.-S.; Kim, D.; Ko, S.-O.; Kang, S. Sustainable harvesting of aqueous phase fatty acids by expanded graphite and isopropyl alcohol. Int. J. Hydrog. Energy 2016, 41, 21780-21786. [CrossRef]

11. Magnacca, G.; Neves Dos Santos, F.; Sadraei, R. Bio-based Substances from Compost as Reactant and Active Phase for Selective Capture of Cationic Pollutants From Waste Water. Front. Chem. 2020, 8, 550. [CrossRef]

12. Ibrahim, M.; Labaki, M.; Giraudon, J.-M.; Lamonier, J.-F. Hydroxyapatite, a multifunctional material for air, water and soil pollution control: A review. J. Hazard. Mater. 2020, 383, 121139. [CrossRef]

13. Fihri, A.; Len, C.; Varma, R.S.; Solhy, A. Hydroxyapatite: A review of syntheses, structure and applications in heterogeneous catalysis. Coord. Chem. Rev. 2017, 347, 48-76. [CrossRef]

14. Kamieniak, J.; Kelly, P.J.; Banks, C.E.; Doyle, A.M. Mechanical, pH and Thermal Stability of Mesoporous Hydroxyapatite. J. Inorg. Organomet. Polym. Mater. 2018, 28, 84-91. [CrossRef]

15. Cawthray, J.F.; Creagh, A.L.; Haynes, C.A.; Orvig, C. Ion Exchange in Hydroxyapatite with Lanthanides. Inorg. Chem. 2015, 54, 1440-1445. [CrossRef] [PubMed] 
16. Diallo-Garcia, S.; Osman, M.B.; Krafft, J.-M.; Casale, S.; Thomas, C.; Kubo, J.; Costentin, G. Identification of Surface Basic Sites and Acid-Base Pairs of Hydroxyapatite. J. Phys. Chem. C 2014, 118, 12744-12757. [CrossRef]

17. Wang, X.; Wang, G.; Marchetti, A.; Wu, L.; Wu, L.; Guan, Y. Preparation of porous hydroxyapatite and its application in Pb ions effective removal. AIP Adv. 2019, 9, 025123. [CrossRef]

18. Wu, Y.; Chen, D.; Kong, L.; Tsang, D.C.W.; Su, M. Rapid and effective removal of uranium (VI) from aqueous solution by facile synthesized hierarchical hollow hydroxyapatite microspheres. J. Hazard. Mater. 2019, 371, 397-405. [CrossRef] [PubMed]

19. Smičiklas, I.; Dimović, S.; Plećaš, I.; Mitrić, M. Removal of Co2+ from aqueous solutions by hydroxyapatite. Water Res. 2006, 40, 2267-2274. [CrossRef]

20. Ferri, M.; Campisi, S.; Gervasini, A. Nickel and cobalt adsorption on hydroxyapatite: A study for the de-metalation of electronic industrial wastewaters. Adsorption 2019, 25, 649-660. [CrossRef]

21. Kadouche, S.; Lounici, H.; Benaoumeur, K.; Drouiche, N.; Hadioui, M.; Sharrock, P. Enhancement of Sedimentation Velocity of Heavy Metals Loaded Hydroxyapatite Using Chitosan Extracted from Shrimp Waste. J. Polym. Environ. 2012, 20, 848-857. [CrossRef]

22. Descamps, M.; Hornez, J.C.; Leriche, A. Manufacture of hydroxyapatite beads for medical applications. J. Eur. Ceram. Soc. 2009, 29, 369-375. [CrossRef]

23. Sopyan, I.; Mel, M.; Ramesh, S.; Khalid, K.A. Porous hydroxyapatite for artificial bone applications. Sci. Technol. Adv. Mater. 2007, 8, 116-123. [CrossRef]

24. Ribeiro, C.C.; Barrias, C.C.; Barbosa, M.A. Preparation and characterisation of calcium-phosphate porous microspheres with a uniform size for biomedical applications. J. Mater. Sci. Mater. Med. 2006, 17, 455-463. [CrossRef] [PubMed]

25. Nijhawan, A.; Butler, E.C.; Sabatini, D.A. Macroporous hydroxyapatite ceramic beads for fluoride removal from drinking water. J. Chem. Technol. Biotechnol. 2017, 92, 1868-1875. [CrossRef]

26. Nijhawan, A.; Butler Elizabeth, C.; Sabatini David, A. Hydroxyapatite Ceramic Adsorbents: Effect of Pore Size, Regeneration, and Selectivity for Fluoride. J. Environ. Eng. 2018, 144, 04018117. [CrossRef]

27. Le, D.T.; Le, T.P.T.; Do, H.T.; Vo, H.T.; Pham, N.T.; Nguyen, T.T.; Cao, H.T.; Nguyen, P.T.; Dinh, T.M.T.; Le, H.V.; et al. Fabrication of Porous Hydroxyapatite Granules as an Effective Adsorbent for the Removal of Aqueous Pb(II) Ions. J. Chem. 2019, $2019,8620181$. [CrossRef]

28. Choy, K.K.H.; McKay, G.; Porter, J.F. Sorption of acid dyes from effluents using activated carbon. Resour. Conserv. Recycl. 1999, 27, 57-71. [CrossRef]

29. Tran, T.N.; Kim, D.-G.; Ko, S.-O. Encapsulation of biogenic manganese oxide and Pseudomonas putida MnB1 for removing 17 $\alpha$-ethinylestradiol from aquatic environments. J. Water Process. Eng. 2020, 37, 101423. [CrossRef]

30. Al-Ghouti, M.A.; Da'ana, D.A. Guidelines for the use and interpretation of adsorption isotherm models: A review. J. Hazard. Mater. 2020, 393, 122383. [CrossRef] [PubMed]

31. Do, Q.C.; Choi, S.; Kim, H.; Kang, S. Adsorption of Lead and Nickel on to Expanded Graphite Decorated with Manganese Oxide Nanoparticles. Appl. Sci. 2019, 9, 5375. [CrossRef]

32. Choi, J.-W.; Choi, N.-C.; Lee, S.-J.; Kim, D.-J. Novel three-stage kinetic model for aqueous benzene adsorption on activated carbon. J. Colloid Interface Sci. 2007, 314, 367-372. [CrossRef] [PubMed]

33. Largitte, L.; Pasquier, R. A review of the kinetics adsorption models and their application to the adsorption of lead by an activated carbon. Chem. Eng. Res. Des. 2016, 109, 495-504. [CrossRef]

34. Gao, M.; Wang, W.; Yang, H.; Ye, B.-C. Hydrothermal synthesis of hierarchical hollow hydroxyapatite microspheres with excellent fluoride adsorption property. Microporous Mesoporous Mater. 2019, 289, 109620. [CrossRef]

35. Sing, K.S.W. Reporting physisorption data for gas/solid systems with special reference to the determination of surface area and porosity (Provisional). Pure Appl. Chem. 1982, 54, 2201-2218. [CrossRef]

36. Dubois, I.E.; Holgersson, S.; Allard, S.; Malmström, M.E. Dependency of BET surface area on particle size for some granitic minerals. Proc. Radiochim. Acta 2011, 1, 75-82. [CrossRef]

37. Aruna, S.T.; Kulkarni, S.; Chakraborty, M.; Kumar, S.S.; Balaji, N.; Mandal, C. A comparative study on the synthesis and properties of suspension and solution precursor plasma sprayed hydroxyapatite coatings. Ceram. Int. 2017, 43, 9715-9722. [CrossRef]

38. Nayak, B.; Samant, A.; Patel, R.; Misra, P.K. Comprehensive Understanding of the Kinetics and Mechanism of Fluoride Removal over a Potent Nanocrystalline Hydroxyapatite Surface. ACS Omega 2017, 2, 8118-8128. [CrossRef]

39. Kang, I.-G.; Park, C.-I.; Lee, H.; Kim, H.-E.; Lee, S.-M. Hydroxyapatite Microspheres as an Additive to Enhance Radiopacity, Biocompatibility, and Osteoconductivity of Poly(methyl methacrylate) Bone Cement. Materials 2018, 11, 258. [CrossRef]

40. Hernández-Cocoletzi, H.; Salinas, R.A.; Águila-Almanza, E.; Rubio-Rosas, E.; Chai, W.S.; Chew, K.W.; Mariscal-Hernández, C.; Show, P.L. Natural hydroxyapatite from fishbone waste for the rapid adsorption of heavy metals of aqueous effluent. Environ. Technol. Innov. 2020, 20, 101109. [CrossRef]

41. Mourabet, M.; El Rhilassi, A.; El Boujaady, H.; Bennani-Ziatni, M.; El Hamri, R.; Taitai, A. Removal of fluoride from aqueous solution by adsorption on hydroxyapatite (HAp) using response surface methodology. J. Saudi Chem. Soc. 2015, 19, 603-615. [CrossRef]

42. Barka, N.; Qourzal, S.; Assabbane, A.; Nounah, A.; AÎT-Ichou, Y. Adsorption of Disperse Blue SBL dye by synthesized poorly crystalline hydroxyapatite. J. Environ. Sci. 2008, 20, 1268-1272. [CrossRef] 
43. Skwarek, E.; Janusz, W.; Sternik, D. The influence of the hydroxyapatite synthesis method on the electrochemical, surface and adsorption properties of hydroxyapatite. Adsorp. Sci. Technol. 2017, 35, 507-518. [CrossRef]

44. Kim, D.-G.; Nhung, T.T.; Ko, S.-O. Enhanced adsorption of heavy metals with biogenic manganese oxide immobilized on zeolite. KSCE J. Civ. Eng. 2016, 20, 2189-2196. [CrossRef]

45. Sulaymon, A.H.; Abid, B.A.; Al-Najar, J.A. Removal of lead copper chromium and cobalt ions onto granular activated carbon in batch and fixed-bed adsorbers. Chem. Eng. J. 2009, 155, 647-653. [CrossRef]

46. Rodríguez, A.; Sáez, P.; Díez, E.; Gómez, J.M.; García, J.; Bernabé, I. Highly efficient low-cost zeolite for cobalt removal from aqueous solutions: Characterization and performance. Environ. Prog. Sustain. Energy 2019, 38, S352-S365. [CrossRef]

47. Wakamura, M.; Kandori, K.; Ishikawa, T. Surface structure and composition of calcium hydroxyapatites substituted with Al(III), $\mathrm{La}(\mathrm{III})$ and Fe(III) ions. Colloid. Surf. A. Physicochem. Eng. Asp. 2000, 164, 297-305. [CrossRef]

48. Khalili, F.I.; Khalifa, A.a.; Al-Banna, G. Removal of uranium(VI) and thorium(IV) by insolubilized humic acid originated from Azraq soil in Jordan. J. Radioanal. Nucl. Chem. 2017, 311, 1375-1392. [CrossRef] 